\title{
Correction to: Ultrasonic P Wave Velocity Measurement of Sedimentary Rocks in Laboratory and Its Dependency on Different Parameters by Using Multivariate Regression Analysis
}

Siddharth Garia, Arnab Kumar Pal, Archana M. Nair, and K. Ravi

\section{Correction to:}

Chapter "Ultrasonic P Wave Velocity Measurement of Sedimentary Rocks in Laboratory and Its Dependency on Different Parameters by Using Multivariate Regression Analysis" in: T. G. Sitharam et al. (eds.), Seismic Hazards and Risk, Lecture Notes in Civil Engineering 116, https://doi.org/10.1007/978-981-15-9976-7_30

The original version of the book was published without the reference to the source of Figure 3 in Chapter 30, which has now been updated as follows: Figure 3 is adapted from a journal publication by Garia et al., 2021 in the Journal of Petroleum Science and Engineering-ELSEVIER. The book and the chapter have been updated with the change. 